\title{
Inhibitor of DNA-binding 4 contributes to the maintenance and expansion of cancer stem cells in 4T1 mouse mammary cancer cell line
}

\author{
Se-Jin Park, Ran-Ju Kim, Jeong-Seok Nam* \\ Laboratory of Tumor Suppressor, Lee Gil Ya Cancer and Diabetes Institute, Gachon University of Medicine and Science, \\ Incheon, Korea
}

\begin{abstract}
The cancer stem cell (CSC) hypothesis proposes that CSCs are the root of cancer. CSC-targeted therapies may prevent cancer relapse and provide more effective treatment. The expression of aldehyde dehydrogenase 1, as assessed by the Aldefluor assay, has been recognized as a marker of CSCs in breast cancer. Inhibitors of DNA-binding proteins (IDs) have an important role in stem cell differentiation. In this study, we examined IDs necessary for the regulation of stem properties in Aldefluor ${ }^{\text {pos }} 4 \mathrm{T1}$ cells. When the expression profile of IDs in Aldefluor ${ }^{\text {neg }}$ and Aldefluor ${ }^{\text {pos }} 4 T 1$ cells was compared, qRT-PCR analysis showed that ID4 expression was highly upregulated in Aldefluor ${ }^{p o s} 4 T 1$ cells. In addition, knockdown of ID4 expression suppressed the properties of CSCs, including their sphere-forming ability and side population phenotype. The findings suggest that ID4 may be a therapeutic target for the treatment of advanced breast cancer.
\end{abstract}

Key words: Breast cancer cell, cancer stem cell, inhibitor of DNA-binding 4

Received 11 November 2011; Revised version received 1 December 2011; Accepted 12 December 2011

Cancer stem cells (CSCS) are a subpopulation of tumor cells that possess tumor initiation and self-renewal capacity. CSCs may be responsible for resistance to conventional therapies that can frequently lead to cancer metastasis and recurrence [1-3]. If so, CSC specific therapies may prevent cancer relapse and completely destroy cancer at the origin.

Aldehyde dehydrogenase (ALDH) is a detoxifying enzyme responsible for oxidizing intracellular aldehydes. The enzyme plays an important role in multiple biological activities. The expression of ALDH1, as assessed by the Aldefluor assay, has been recognized as a marker for normal and malignant human mammary stem cells [4]. Especially, breast CSCs with elevated ALDH activity are highly tumorigenic in a NOD/ SCID xenograft model [4]. Clinical data suggest that high ALDH1 expression is correlated with poor clinical outcome in breast cancer patients [4-6]. Collectively, these studies support the view that $\mathrm{ALDH} 1$ may be a relevant $\mathrm{CSC}$ marker in breast cancer.

Inhibitors of DNA-binding proteins (IDs) are transcription factors that antagonize the DNA-binding capacity of basic helix-loop-helix factors. IDs regulate cell cycle and cell differentiation, and have an important role in the control of stem cell self-renewal $[7,8]$. Elevated expression of IDs in neural stem cells increases self-renewal and proliferation [9]. Furthermore, IDs expression is elevated in various tumor cell lines $[10,11]$. Together, these studies suggest a possible link between CSCs and IDs expression. The 4T1 cell line is widely considered to be one of the best mouse mammary cancer cell lines for the study of human cancer progression $[12,13]$. Therefore, in this study, we used 4T1 mouse mammary cancer cells to investigate IDs necessary for cancer stemness, with the goal of determining those IDs that could be feasible targets for stem-specific cancer therapy.

\footnotetext{
*Corresponding author: Jeong-Seok Nam, Laboratory of Tumor Suppressor, Lee Gil Ya Cancer and Diabetes Institute, Gachon University of Medicine and Science, 7-45 Songdo-dong, Yeonsu-gu, Incheon 406-840, Korea Tel: +82-32-899-6072; Fax: +82-32-899-6350; E-mail: namjs@gachon.ac.kr
}

This is an Open Access article distributed under the terms of the Creative Commons Attribution Non-Commercial License (http://creativecommons.org/licenses/ by-nc/3.0) which permits unrestricted non-commercial use, distribution, and reproduction in any medium, provided the original work is properly cited. 


\section{Materials and Methods}

\section{Cell culture}

The 4T1 mouse mammary cancer cell line was cultured in DMEM (Invitrogen, Grand Island, NY, USA) containing 10\% fetal bovine serum and $1 \%$ penicillin/Streptomycin (Invitrogen) as previously described [14].

\section{Flow cytometry}

Cell sorting and side population (SP) analysis were performed using FACS Aria and FACS LSRII machines (Becton Dickinson, Franklin Lakes, NJ, USA), respectively. FACS data were analyzed using Flowjo software (Tree star, Ashland, OR, USA). The Aldefluor kit (Stem Cell Technologies, Vancouver, BC, Canada) was used to isolate cell populations with elevated ALDH1 activity, according to the manufacturer's instructions.

\section{Quantitative reverse-transcription-PCR (qRT-PCR)}

qRT-PCR was performed using SYBR green PCR master mix (Applied Biosystems, Foster City, CA, USA) and the ABI 7300 real-time PCR system according to the manufacturer's instructions. Mouse mRNA levels were normalization to mouse hypoxanthine-guanine phosphoribosyltransferase (HPRT). The primer details sets were:

ID1: 5'-TGCTCTCGGTTCCCCAGGGG-3' (forward) 5'-CCCACTGGACCGATCCGCCA-3' (reverse)

ID2: 5'-TCTGGGGGATGCTGGGCACC-3' (forward) 5'-GCTTGGGCATCTCCCGGAGC-3' (reverse)

ID3: 5'-CTACTCGCGCCTGCGGGAAC-3' (forward) 5'-CGGCTCTGCCAGGACCACCT-3' (reverse)

ID4: 5'-GCTCGTGCCTACCATCCCGC-3' (forward) 5'-GGTGGCGGCTGTCTCAGCAAA-3' (reverse)

ABCG2: 5'-GAACATCGGCCTTCAAAGAGC-3' (forward) 5'-GGCACCAATAATAAGCCCCAGT-3' (reverse)

ABCB1: 5'-CAACAGCCGGGCCGTGTCTC-3' (forward) 5'-GCTGCTTCTGCCCACCCGAC-3' (reverse)

ABCA1: 5'-CTCCCGTGCCAACCTGGCAG-3' (forward) 5'-GCCAGGCTACGCACAGCACA-3' (reverse)

ABCA2: 5'-GCATTCAAACTGAGGCACCA-3' (forward) 5'-GACAGCCGTAATCGGTACTCCT-3' (reverse)

ABCC1: 5'-TCGCCATGACCGGGGCTACA-3' (forward) 5'-GGGCTCGGAGCACTCCCTGA-3' (reverse)

ABCC2: 5'-GGAGGCAGTACACGATTGGAGA-3' (forward) 5'-GGTCACGTCCATTAGCTTCCTGG-3' (reverse)

ABCC3: 5'-GATCCTGAACGGCATCAAAGTG-3' (forward) 5'-TCCСТTTCACCTGCTCCAAGA-3' (reverse)

HPRT: 5'-GCCTAAGATGAGCGCAAGTTG-3' (forward) 5'-TACTAGGCAGATGGCCA CAGG-3' (reverse)
Immunoblot analysis

Immunoblot analysis was performed as previously described [14]. Antibodies to the following proteins were used: ID4 (Santa Cruz Biotechnology, Santa Cruz, CA, USA) and $\beta$ actin (Sigma-Aldrich, St. Louis, MO, USA).

\section{Tumorsphere culture}

Tumorsphere culture was performed in low attachment dishes (Corning, New York, NY, USA), supplemented with B27 (Invitrogen), $20 \mathrm{ng} / \mathrm{mL}$ epidermal growth factor (EGF), $20 \mathrm{ng} / \mathrm{mL}$ basic fibroblast growth factor (bFGF; Peprotech, Rocky Hill, NJ, USA) and $4 \mathrm{~g} / \mathrm{mL}$ heparin (Sigma-Aldrich). After 7-day culture, wells were examined under an inverted microscope at $\times 50$ magnification, and the number and diameter of spheres was counted for in independent fields per well using the Image-Pro Plus program (Media Cybernetics, Silver Spring, MD, USA).

\section{Small interfering RNA (siRNA)}

siRNA specific to ID4 (Cat no: M-043687-01) and nontargeting siRNA (Cat No: D-001206-13-05) were purchased from Dharmacon (Lafayette, CO, USA). Transfection was performed using DharmaFECT (Dharmacon), according to the manufacturer's instructions. Cells were treated for 2 days with siRNA at a final concentration of $100 \mathrm{nM}$.

\section{Statistical analysis}

All experiments were done three or more times, and the results are expressed as mean $\pm \mathrm{SD}$. Statistical analyses of these data were done using an unpaired Student's $t$ test for parametric analysis or the Mann-Whitney $U$ test for nonparametric analysis.

\section{Results}

\section{Aldefluor ${ }^{\text {pos }}$ cell population has high ID4 expression}

The expression of ALDH1, as assessed by the Aldefluor assay, has been recognized as a CSC marker in breast cancer [4]. To evaluate IDs expression in CSC population characterized by high ALDH1 activity, we compared the expression of IDs in Aldefluor ${ }^{\text {neg }}$ and Aldefluor ${ }^{\text {pos }}$ cell populations sorted from 4T1 cells (Figure 1A). qRT-PCR analysis showed a significant increase (approximately 2.5-fold) of ID4 gene expression but no significant change of ID1, ID2, and ID3 expression in Aldefluor $^{\text {pos }} 4 \mathrm{~T} 1$ cell population compared to the Aldefluor ${ }^{\text {neg }}$ 4T1 cell population (Figure 1B). 

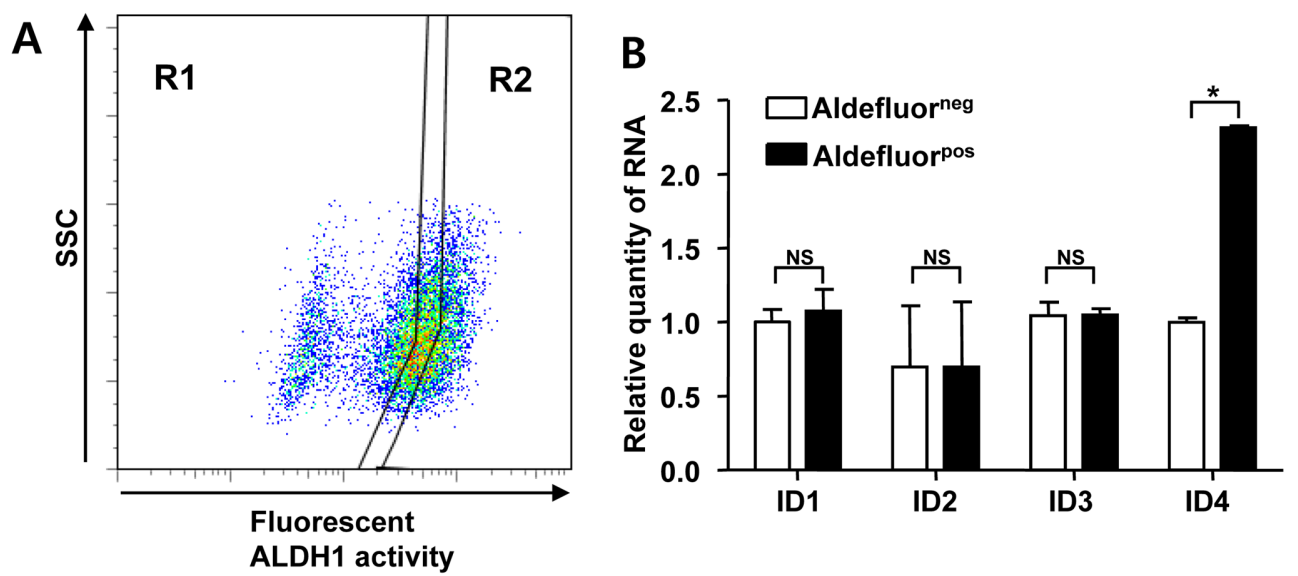

Figure 1. The Aldefluor ${ }^{\text {pos }}$ cell population has high ID4 expression. (A) The dot plots show the percentage of Aldefluor ${ }^{\text {neg }}$ (R1) and Aldefluor $^{\text {pos }}$ (R2) cells from 4T1 cells. (B) The expression profile of IDs in Aldefluor ${ }^{\text {neg }}$ and Aldefluor ${ }^{\text {pos }} 4 T 1$ cells. qRT-PCR was performed using primers for IDs. Values are mean \pm SD. ${ }^{*} P<0.05$ is a statistically significant difference.

A

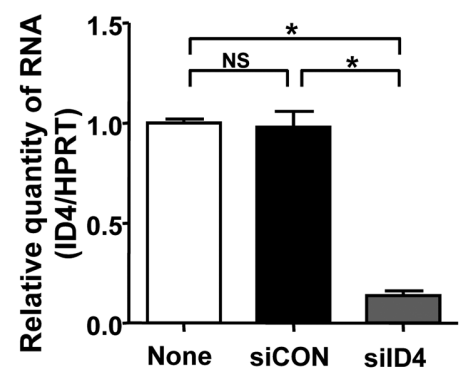

C

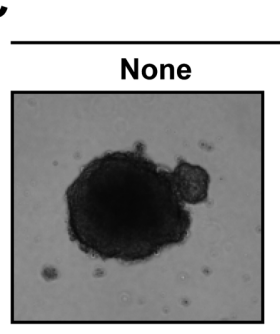

4T1 sicON

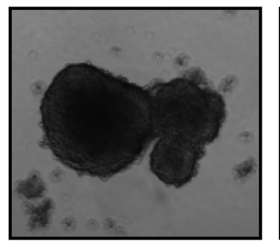

B
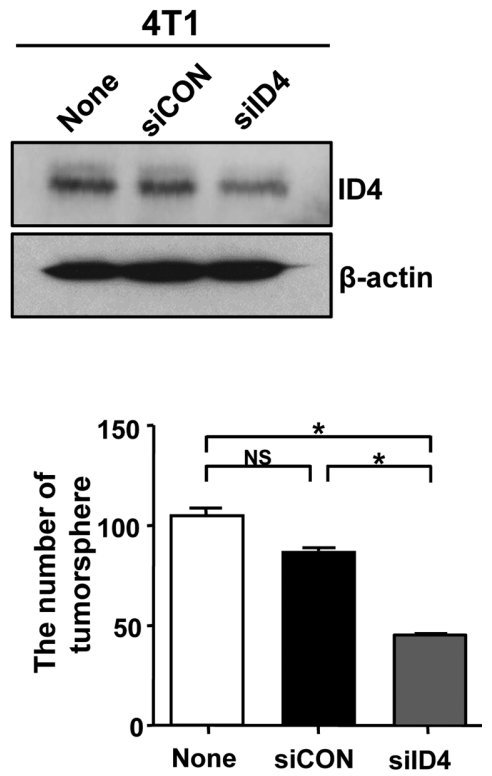

Figure 2. Knockdown of ID4 expression suppresses tumorsphere-forming ability. (A and B) qRT-PCR and immunoblot analysis for ID4 in control (Non, non-transfected cells), siCon (control siRNA) or silD (ID4 siRNA)-transfected 4T1 cells. (C) Effects of ID4 knockdown on tumorsphere formation in 4T1 cells. After siRNA transfection under adherent conditions, cells were detached and suspension cultured under serum free conditions for 7 days. Values are mean $\pm S D$. ${ }^{*} P<0.05$ is a statistically significant difference. Scale bar $=100 \mu \mathrm{m}$.

Knockdown of ID4 inhibits tumorsphere forming ability

To investigate whether ID4 influences the properties of CSCs, siRNA technology was used to knockdown ID4 in 4T1 cells. qRT-PCR and immunoblot analyses showed that ID4 expression was efficiently suppressed in $4 \mathrm{~T} 1$ cells transfected with ID4 targeted siRNA (silD4), whereas non-transfected cells (None) and cells transfected with control siRNA (siCON) had similar ID4 expression (Figures 2A and 2B). The sphere forming assay is considered to demonstrate the self-renewing ability of stem cells. ID4 knockdown in $4 \mathrm{~T} 1$ cells reduced the efficiency of formation of tumorsphere more than 100 min diameter (Figure 2C).

\section{Knockdown of ID4 reduces SP fractions and $\mathrm{ABCC} 3$ expression}

The SP phenotype is associated with the characteristics of CSCs [15]. To determine whether ID4 affects the SP fraction, cells were stained with Hoechst 33342, which is actively extruded by verapamil-sensitive ATP-binding cassette (ABC) transporter. Flow cytometry analysis showed an approximately 2.6-fold decrease of the SP fraction in ID4 siRNA-transfected 
A

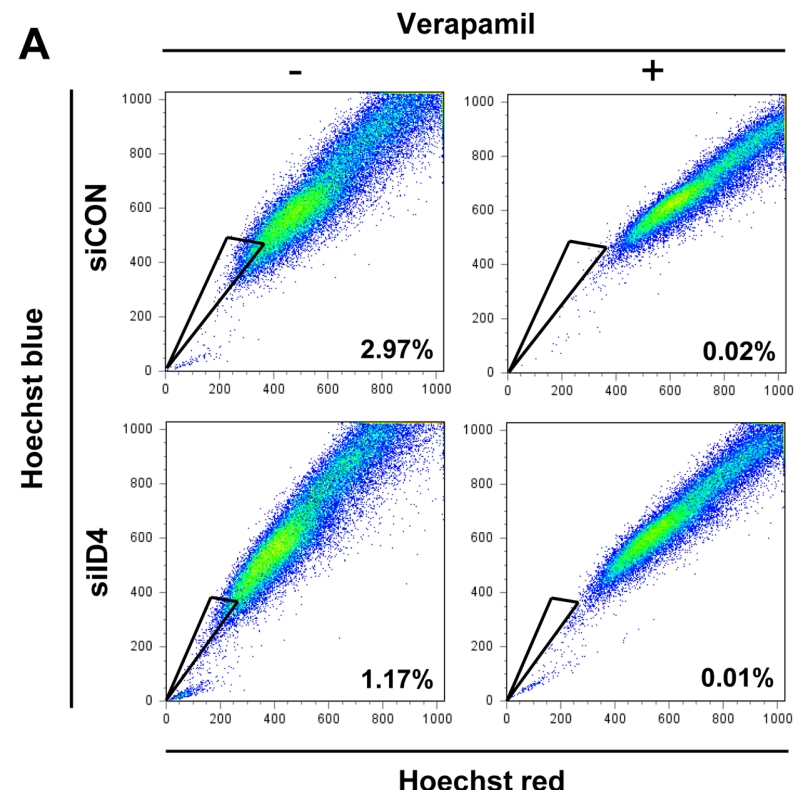

Verapamil

B

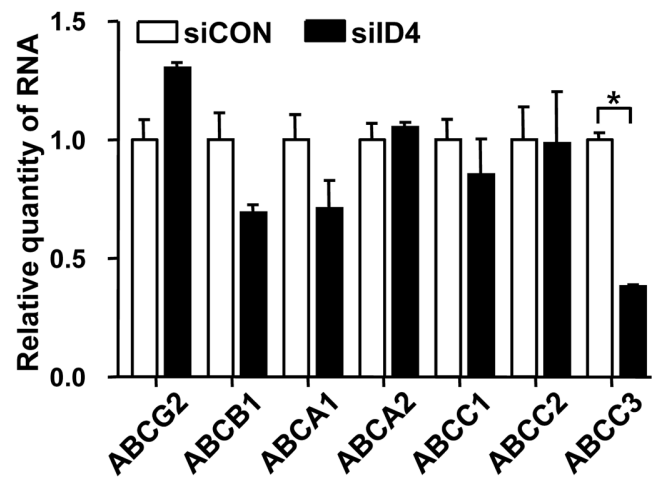

Figure 3. ID4 knockdown affects SP fraction and ABCC3 expression. (A) Representative SP phenotype from 4T1 cells transfected with non-specific control siRNA (siCON) of ID4-targeted siRNA (silD4). The SP fraction, which actively pumps out the Hoechst dye, is identified as the poorly staining cell population (black triangle) that largely disappears when the $A B C$ transporters are inhibited with verapamil. (B) qRT-PCR analysis of ABC transporters expression in 4T1 cells following transfection with siCON or silD4. Values are mean $\pm S D$. ${ }^{*} P<0.05$ is a statistically significant difference.
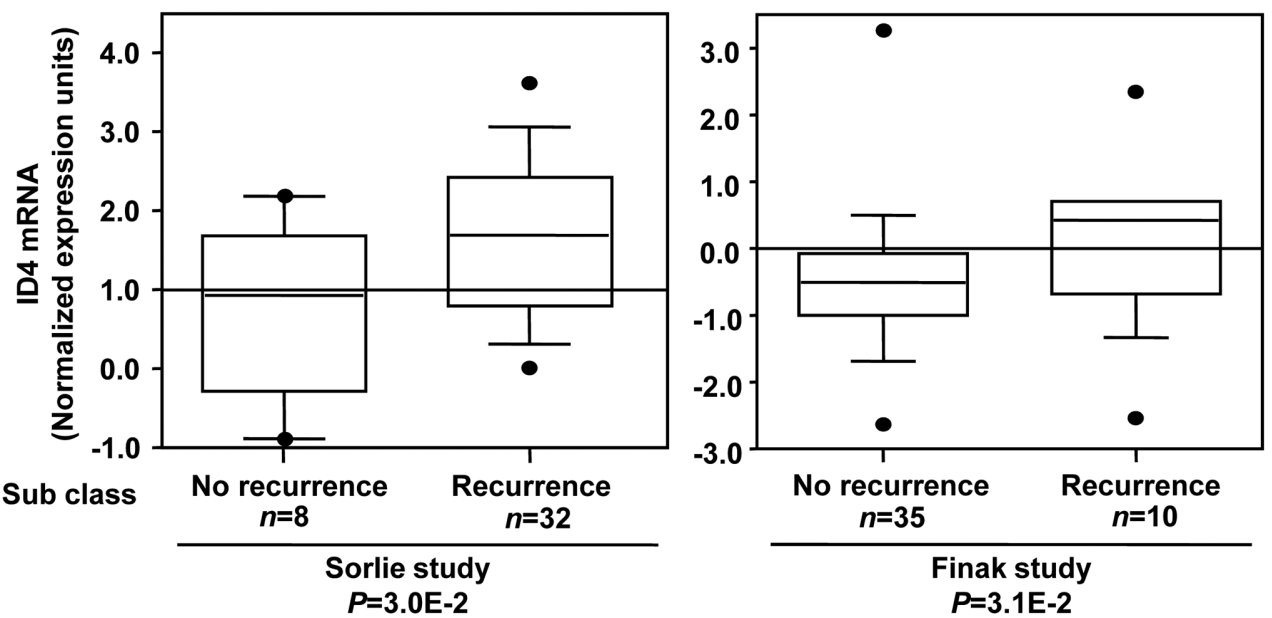

Figure 4. ID4 mRNA expression in human breast tumors as a function of recurrent status (extracted from Sorlie et al [16] and Finak et al [17]). In silico analysis of published clinical microarray data was performed using database and analysis tools (http:// www.oncomine.org).

4T1 cells, compared with their counterparts (Figure 3A). Recent evidence suggests that the SP fraction highly expresses the ABC transporters [15]. We also examined whether knockdown of ID4 affects the expression of $\mathrm{ABC}$ transporters in $4 \mathrm{~T} 1$ cells. qRT-PCR analysis showed an approximately 3-fold decrease of $A B C C 3$ expression but no significant change of the other $\mathrm{ABC}$ transporter's expression.

IDs expression is elevated in recurrent breast cancers The CSC hypothesis proposes that CSCs are the root of cancer and contribute to cancer recurrence [1,2]. In silico analysis of results from large clinical microarray studies $[16,17]$ showed ID4 mRNA levels correlated positively with recurrence in human breast cancer (Figure 4).

\section{Discussion}

IDs have been recognized as prominent regulators of stem cell fate decisions $[18,19]$. In this study, we investigated the IDs that are necessary for the regulation of CSCs in $4 \mathrm{~T} 1$

Lab Anim Res | December, 2011 | Vol. 27, No. 4 
mouse mammary cancer cells. To our best knowledge, our study is the first experimental report showing that inhibition of ID4 may attenuate the maintenance and expansion of breast CSCs.

High ID4 expression in glioma is implicated in malignant cancer progression [20]. Several recent studies reported that experimental overexpression of ID4 dedifferentiates Ink4a/ Arf $^{-/}$mouse astrocytes and glioma cells to glioma stem-like cells (GSCs) and enhances drug resistance of GSCs [21,22]. Collectively, the previous and present data provide evidence that high ID4 expression enhances properties of stem cells in cancers.

We especially observed a decrease of the SP fraction in ID4 siRNA-transfected 4T1 cells compared with their counterparts. SP cells can rapidly efflux lipophilic fluorescent dyes to produce a characteristic profile based on fluorescenceactivated flow cytometric analysis. The SP phenotype might facilitate the enrichment of CSCs and SP fractions have the capacity for both self-renewal and proliferation and to be largely responsible for in vivo malignancy [23]. The biological basis for the differential efflux of these dyes out of the cells is associated with the presence of transmembrane proteins, such as ABC transporters [24]. Several transporters may contribute to the malignant SP phenotype, such as ABCG2 and $\mathrm{ABCA} 3$ in the neuroblastoma or leukemia SP fraction $[15,25]$. It has been reported that the plasma expression of $\mathrm{ABCC} 2$ and $\mathrm{ABCC} 3$ may contribute to the chemoresistance phenotype of hepatocellular carcinoma [26]. Therefore, we examined whether ID4 affects the expression of an ABC transporter, after confirming that knockdown of ID4 expression suppressed the SP phenotype in 4T1 cells. Our results show that knockdown of ID4 expression decreased ABCC3 expression compared with controls. These data suggest that ID4 expression stimulates cultured mouse mammary cancer cells to adopt characteristics of stem cells, partly through the regulation of $\mathrm{ABCC} 3$ expression. However, the present data do not fully explain the molecular mechanisms of ID4 in cancer stemness. Thus, we are still investigating possible mechanisms.

In summary, the therapeutic targeting of ID4 may be useful for the treatment of breast CSCs. We predict that the further characterization of the specific role of ID4 in CSC signaling complexes will aid in the development of more effective cancer therapies.

\section{Acknowledgment}

This research was supported by Basic Science Research Program through the National Research Foundation of Korea
(NRF) funded by the Ministry of Education, Science and Technology (2010-0002771).

\section{References}

1. Dean $M$, Fojo $T$, Bates $S$. Tumour stem cells and drug resistance. Nat Rev Cancer 2005; 5: 275-284.

2. Charafe-Jauffret E, Monville F, Ginestier C, Dontu G, Birnbaum D, Wicha MS. Cancer stem cells in breast: current opinion and future challenges. Pathobiology 2008; 75: 7584.

3. Gangemi R, Paleari L, Orengo AM, Cesario A, Chessa L, Ferrini S, Russo P. Cancer stem cells: a new paradigm for understanding tumor growth and progression and drug resistance. Curr Med Chem 2009; 16: 1688-1703.

4. Ginestier $\mathrm{C}$, Hur MH, Charafe-Jauffret $E$, Monville $F$, Dutcher J, Brown M, Jacquemier J, Viens P, Kleer CG, Liu S, Schott A, Hayes D, Birnbaum D, Wicha MS, Dontu G. ALDH1 is a marker of normal and malignant human mammary stem cells and a predictor of poor clinical outcome. Cell Stem Cell 2007; 1: 555-567.

5. Morimoto K, Kim SJ, Tanei T, Shimazu K, Tanji Y, Taguchi T, Tamaki Y, Terada N, Noguchi S. Stem cell marker aldehyde dehydrogenase 1-positive breast cancers are characterized by negative estrogen receptor, positive human epidermal growth factor receptor type 2, and high Ki67 expression. Cancer Sci 2009; 100: 1062-1068.

6. Marcato P, Dean CA, Pan D, Araslanova R, Gillis M, Joshi M, Helyer L, Pan L, Leidal A, Gujar S, Giacomantonio CA, Lee PW. Aldehyde dehydrogenase activity of breast cancer stem cells is primarily due to isoform ALDH1A3 and its expression is predictive of metastasis. Stem Cells 2011; 29: 32-45.

7. Lee JE, Hollenberg SM, Snider L, Turner DL, Lipnick N, Weintraub H. Conversion of Xenopus ectoderm into neurons by NeuroD, a basic helix-loop-helix protein. Science 1995; 268:836-44.

8. Ma Q, Chen Z, del Barco Barrantes I, de la Pompa JL, Anderson DJ. neurogenin1 is essential for the determination of neuronal precursors for proximal cranial sensory ganglia. Neuron 1998; 20: 469-482.

9. Jung $S$, Park RH, Kim S, Jeon YJ, Ham DS, Jung MY, Kim SS, Lee YD, Park $\mathrm{CH}$, Suh-Kim H. Id proteins facilitate selfrenewal and proliferation of neural stem cells. Stem Cells Dev 2010; 19: 831-841.

10. Fukuma $M$, Okita $H$, Hata J, Umezawa A. Upregulation of Id2, an oncogenic helix-loop-helix protein, is mediated by the chimeric EWS/ets protein in Ewing sarcoma. Oncogene 2003; 22: 1-9.

11. Nishimori $H$, Sasaki $Y$, Yoshida $K$, Irifune $H$, Zembutsu $H$, Tanaka T, Aoyama T, Hosaka T, Kawaguchi S, Wada T, Hata J, Toguchida J, Nakamura Y, Tokino T. The Id2 gene is a novel target of transcriptional activation by EWS-ETS fusion proteins in Ewing family tumors. Oncogene 2002; 21: 8302-8309.

12. Aslakson CJ, Miller FR. Selective events in the metastatic process defined by analysis of the sequential dissemination of subpopulations of a mouse mammary tumor. Cancer Res 1992; 52: 1399-1405.

13. Lelekakis M, Moseley JM, Martin TJ, Hards D, Williams E, Ho P, Lowen D, Javni J, Miller FR, Slavin J, Anderson RL. A novel orthotopic model of breast cancer metastasis to bone. Clin Exp Metastasis 1999; 17: 163-170.

14. Kim RJ, Kim SR, Roh KJ, Park SB, Park JR, Kang KS, Kong G, Tang B, Yang YA, Kohn EA, Wakefield LM, Nam JS. Ras activation contributes to the maintenance and expansion of Sca-1pos cells in a mouse model of breast cancer. Cancer Lett 2010; 287: 172-181.

15. Hirschmann-Jax C, Foster AE, Wulf GG, Nuchtern JG, Jax 
TW, Gobel U, Goodell MA, Brenner MK. A distinct "side population" of cells with high drug efflux capacity in human tumor cells. Proc Natl Acad Sci USA 2004; 101: 1422814233.

16. Sorlie T, Perou CM, Tibshirani R, Aas T, Geisler $\mathrm{S}$, Johnsen $\mathrm{H}_{\text {, }}$ Hastie $T$, Eisen $M B$, van de Rijn $M$, Jeffrey $S S$, Thorsen $T$, Quist $\mathrm{H}$, Matese JC, Brown PO, Botstein D, Eystein Lonning P, Borresen-Dale AL. Gene expression patterns of breast carcinomas distinguish tumor subclasses with clinical implications. Proc Natl Acad Sci USA 2001; 98: 1086910874.

17. Finak G, Bertos $N$, Pepin $F$, Sadekova $S$, Souleimanova $M$, Zhao $H$, Chen $H$, Omeroglu G, Meterissian S, Omeroglu A, Hallett M, Park M. Stromal gene expression predicts clinical outcome in breast cancer. Nat Med 2008; 14: 518-527.

18. Alani RM, Young AZ, Shifflett CB. Id1 regulation of cellular senescence through transcriptional repression of p16/Ink4a. Proc Natl Acad Sci USA 2001; 98: 7812-7816.

19. Yun K, Mantani A, Garel S, Rubenstein J, Israel MA. Id4 regulates neural progenitor proliferation and differentiation in vivo. Development 2004; 131: 5441-5448.

20. Zeng W, Rushing EJ, Hartmann DP, Azumi N. Increased inhibitor of differentiation 4 (Id4) expression in glioblastoma: a tissue microarray study. J Cancer 2010; 1: 1-5.
21. Jeon HM, Jin X, Lee JS, Oh SY, Sohn YW, Park HJ, Joo KM, Park WY, Nam DH, DePinho RA, Chin L, Kim H. Inhibitor of differentiation 4 drives brain tumor-initiating cell genesis through cyclin E and notch signaling. Genes Dev 2008; 22: 2028-2033.

22. Jeon HM, Sohn YW, Oh SY, Kim SH, Beck S, Kim S, Kim H. ID4 imparts chemoresistance and cancer stemness to glioma cells by derepressing miR-9*-mediated suppression of SOX2. Cancer Res 2011; 71: 3410-3421.

23. Bunting KD, Zhou S, Lu T, Sorrentino BP. Enforced Pglycoprotein pump function in murine bone marrow cells results in expansion of side population stem cells in vitro and repopulating cells in vivo. Blood 2000; 96: 902-909.

24. Visvader JE, Lindeman GJ. Cancer stem cells in solid tumours: accumulating evidence and unresolved questions. Nat Rev Cancer 2008; 8: 755-768.

25. Norwood K, Wang RY, Hirschmann-Jax C, Andreeff M, Brenner MK, Goodell MA, Wulf GG. An in vivo propagated human acute myeloid leukemia expressing ABCA3. Leuk Res 2004; 28: 295-299.

26. Nies AT, Konig J, Pfannschmidt M, Klar E, Hofmann WJ, Keppler D. Expression of the multidrug resistance proteins MRP2 and MRP3 in human hepatocellular carcinoma. Int J Cancer 2001; 94: 492-499. 